\title{
Guar Gum as Corrosion Inhibitor for Carbon Steel in Sulfuric Acid Solutions
}

\author{
M. Abdallah* \\ Chemistry Department, Faculty of Science, Benha University, Benha, Egypt
}

Received 31 May 2003; accepted in revised form 26 February 2004

\begin{abstract}
Guar gum was tested as corrosion inhibitor for carbon steel in $1 \mathrm{M} \mathrm{H}_{2} \mathrm{SO}_{4}$ solution using weight loss and Tafel polarization techniques. The results showed that the inhibition efficiency increases with the increasing of the guar gum concentration, which act as an inhibitor of the mixed type. The inhibition action of guar gum was discussed in terms of its horizontal adsorption on the metal surface. The adsorption follows Langmuir adsorption isotherm. The effect of the presence of chloride ion in pitting corrosion was analyzed by the potentiodynamic anodic polarization technique. The pitting corrosion potential changes with the concentration of $\mathrm{Cl}^{-}$ion according to a sigmoid S-shaped curve. This behaviour was explained on the basis of the formation of passivatable, active and continuously propagated pits.
\end{abstract}

Keywords: Guar gum, C-steel, corrosion inhibitor, pitting potential, adsorption.

\section{Introduction}

The corrosion behaviour of carbon steel in acidic solution is a subject of pronounced practical significance considering its widespread applications, namely in the manufactures of pipe lines for petroleum industries. Acid solutions are commonly used in the removal of rust and scale developed in industrial process. However, the presence of halide ions in the solution such as the chloride may provoke pitting corrosion on the steel alloys. Some organic compounds have shown good inhibitor properties to protect steel against corrosion in acidic media

\footnotetext{
*E-mail address: metwally552@hotmail.com
} 
[1-7]. The existing data show that those compounds act by a mechanism of adsorption on the metal surface. This phenomenon is strongly dependent on the nature and surface charge of the metal, the type of aggressive electrolyte and the chemical structure of the inhibitor [8]. Meanwhile, the most important prerequisite for compounds to be efficient inhibitors is that they should chemisorb on the metal surface forming a thickness barrier layer.

Unfortunately, most of the corrosion inhibitors are expensive synthetic chemicals having hazardous properties to living creatures and environments. So, it is very important to choose cheap and safely handled compounds to be used as corrosion inhibitors. The recent research by the electrochemists and corrosion engineers tried to find naturally organic substances or biodegradable organic materials to be used as inhibitors. Thus, the guar gum represents a category of organic compounds that fulfill the mainly aspects needed for such purpose, since, it is naturally occurring and relatively cheap. Guar gum is a polysaccharide consisting of straight chain of D-mannopyranose units joined by $\beta-(1 \rightarrow 4)$ linkage with a side-branching unit of a single D-galactopyranose unit joined to every other mannose unit by $\alpha-(1 \rightarrow 6)$ linkages, which structure is shown in Fig. 1. The food and pharmaceutical industries are the principle applications of guar gum used as a disintegrating and binding agent in compressed tablets.

The aim of this study is to investigate the ability of guar gum to protect the carbon steel against corrosion in $1 \mathrm{M} \mathrm{H}_{2} \mathrm{SO}_{4}$ by using chemical (weight loss) and electrochemical (anodic and cathodic Tafel polarization) methods. The potentiodynamic anodic polarization technique is also used to check the inhibition effect of guar gum on the pitting corrosion of carbon steel in $1 \mathrm{M}$ $\mathrm{H}_{2} \mathrm{SO}_{4}$ containing $\mathrm{NaCl}$ solution.

\section{Experimental Methods}

The weight composition of the carbon steel type (L- 52) is the following: $0.26 \%$ C, $1.35 \% \mathrm{Mn}, 0.04 \% \mathrm{P}, 0.05 \% \mathrm{~S}, 0.05 \% \mathrm{Nb}, 0.02 \% \mathrm{~V}, 0.03 \% \mathrm{Ti}$ and the remainder is iron. Carbon steel sheets with double side's surface area of $3 \mathrm{~cm}^{2}$ were used for weight loss measurements, while for the polarization trials was 
used a cylindrical rod embedded in araldite with an exposed surface area of 1.0 $\mathrm{cm}^{2}$. Before each experimental, the electrodes were polished with different grade emery papers, degreased with acetone, rinsed under running water and finally dried between two filters paper.

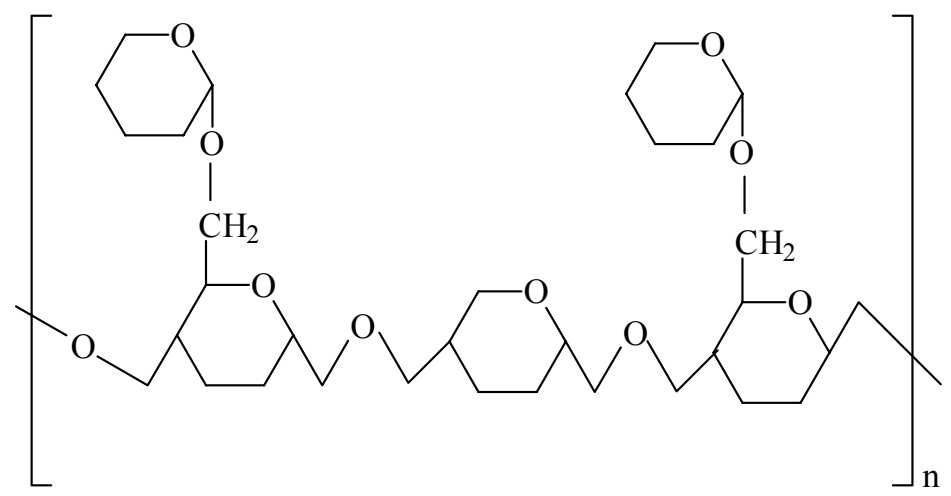

Figure 1. Segment of a guar gum molecule. The polysaccharide backbone is composed of D-mannopyranose units, while the pendant groups are D-galactopyranose units.

The weight loss measurements were carried out as described elsewhere [9]. The specimens were immersed in $50 \mathrm{~mL}$ of test solution during 24 hours. The anodic and cathodic polarization have been performed with a EG \& G model 173 potentiostat / galvanostat equipment using a platinum foil as the auxiliary electrode. The electrode potential was measured against a saturated calomel electrode (SCE). Details of the experimental procedure, electrolytic cell and electrical circuit are fully described earlier [10].

The potentiodynamic anodic polarization was performed at a scanning rate of 1 $\mathrm{mV} / \mathrm{sec}$ using a Wenking potentioscan Type POS 73, and the current densitypotential curves were recorded on a X-Y recorder Type PL-3. The potentials were measured relative to a saturated calomel electrode (SCE), and the electrolytic cell was all pyrex and is described elsewhere [11]. 


\section{Results and Discussion}

\section{Weight loss measurements}

The loss in weight of carbon steel strips in $1 \mathrm{M} \mathrm{H}_{2} \mathrm{SO}_{4}$ solution in absence and presence of different concentrations of guar gum during 24 hours of the trials has been determined.

The protection efficiency $(\mathrm{P} \%)$ and the parameter $(\theta)$ that represents the weight of the metal surface covered by inhibitor molecules were calculated using the following equations:

$$
\begin{aligned}
\mathrm{P} \% & =\left[1-\frac{\mathrm{W}_{\text {add }}}{\mathrm{W}_{\text {fre }}}\right] 100 \\
\theta & =\left[1-\frac{\mathrm{W}_{\text {add }}}{\mathrm{W}_{\text {free }}}\right]
\end{aligned}
$$

where $\mathrm{W}_{\text {free }}$ and $\mathrm{W}_{\text {add }}$, respectively, are the weight loss in the absence and the presence of inhibitor. The calculated values of $\mathrm{P} \%$ and $\theta$ are listed in Table 1.

Table 1. The effect of the presence of guar gum on the protection efficiency of carbon steel corrosion immersed in $1 \mathrm{M} \mathrm{H}_{2} \mathrm{SO}_{4}$ solution as obtained from weight loss measurements.

\begin{tabular}{lcc}
\hline Inhibitor conc. & $\mathrm{P} \%$ & $\theta$ \\
\hline $250 \mathrm{ppm}$ & 75.63 & 0.756 \\
$500 \mathrm{ppm}$ & 85.22 & 0.852 \\
$750 \mathrm{ppm}$ & 90.12 & 0.901 \\
$1000 \mathrm{ppm}$ & 93.18 & 0.932 \\
$1500 \mathrm{ppm}$ & 93.88 & 0.939 \\
\hline
\end{tabular}

Table 1 reveals that the protection efficiency increases with an increase in inhibitor concentration. This behaviour could be attributed to the increase of the surface coverage $(\theta)$ by the adsorption of inhibitor on the steel surface. Attempts were made to fit $\theta$ values to the Frumkin, Freundlich, Langmuir and Temkin 
isotherms. The best fit was obtained with Langmuir isotherm according to the following equation:

$$
\frac{\theta}{1-\theta}=\mathrm{KC}
$$

and rearranging it gives:

$$
\frac{\mathrm{C}}{\theta}=\frac{1}{\mathrm{~K}}+\mathrm{C}
$$

The plotting of $\mathrm{C} / \theta$ against $\mathrm{C}$ gives a straight line with unit slope, Fig. 2. This indicates that adsorption of guar gum on carbon steel surface in $1 \mathrm{M} \mathrm{H}_{2} \mathrm{SO}_{4}$ solution follows Langmuir's adsorption isotherm and consequently, there is no interaction between the molecules adsorbed at the metal surface.

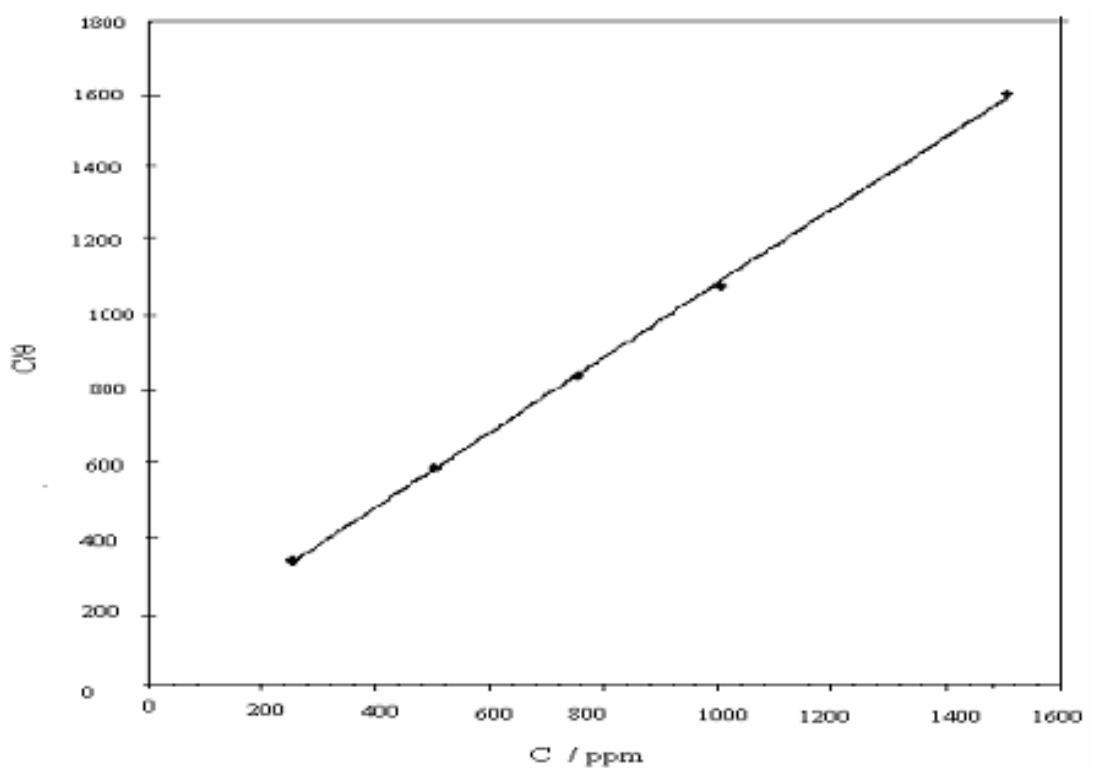

Figure 2. Relationship between inhibitor concentration (C) and $\mathrm{C} / \theta$.

\section{Anodic and cathodic Tafel polarization}

Fig. 3 shows the effect of guar gum concentration on the anodic and cathodic Tafel polarization curves of carbon steel in $1 \mathrm{M} \mathrm{H}_{2} \mathrm{SO}_{4}$ solution. It is clear from these experimental data that guar gum shifts both anodic and cathodic branches of polarization curves to lower values of current density, indicating the inhibition of both the hydrogen evolution (h.e.r) and steel dissolution reactions [12]. This 
may be ascribed to adsorption of guar gum molecule over the corroded surface. The values of anodic $\left(\beta_{\mathrm{a}}\right)$ and cathodic $\left(\beta_{\mathrm{c}}\right)$ Tafel constants were calculated from the linear regions of the polarization curves. The corrosion current $\left(\mathrm{i}_{\text {corr }}\right)$ and exchange current $\left(\mathrm{i}_{\mathrm{o}}\right)$ densities were determined from the intersection of the extrapolated Tafel lines (linear part) with the current axis at stationary corrosion potential $\left(\mathrm{E}_{\mathrm{corr}}\right)$ and at the equilibrium potential of hydrogen evolution reaction (h.e.r), respectively.

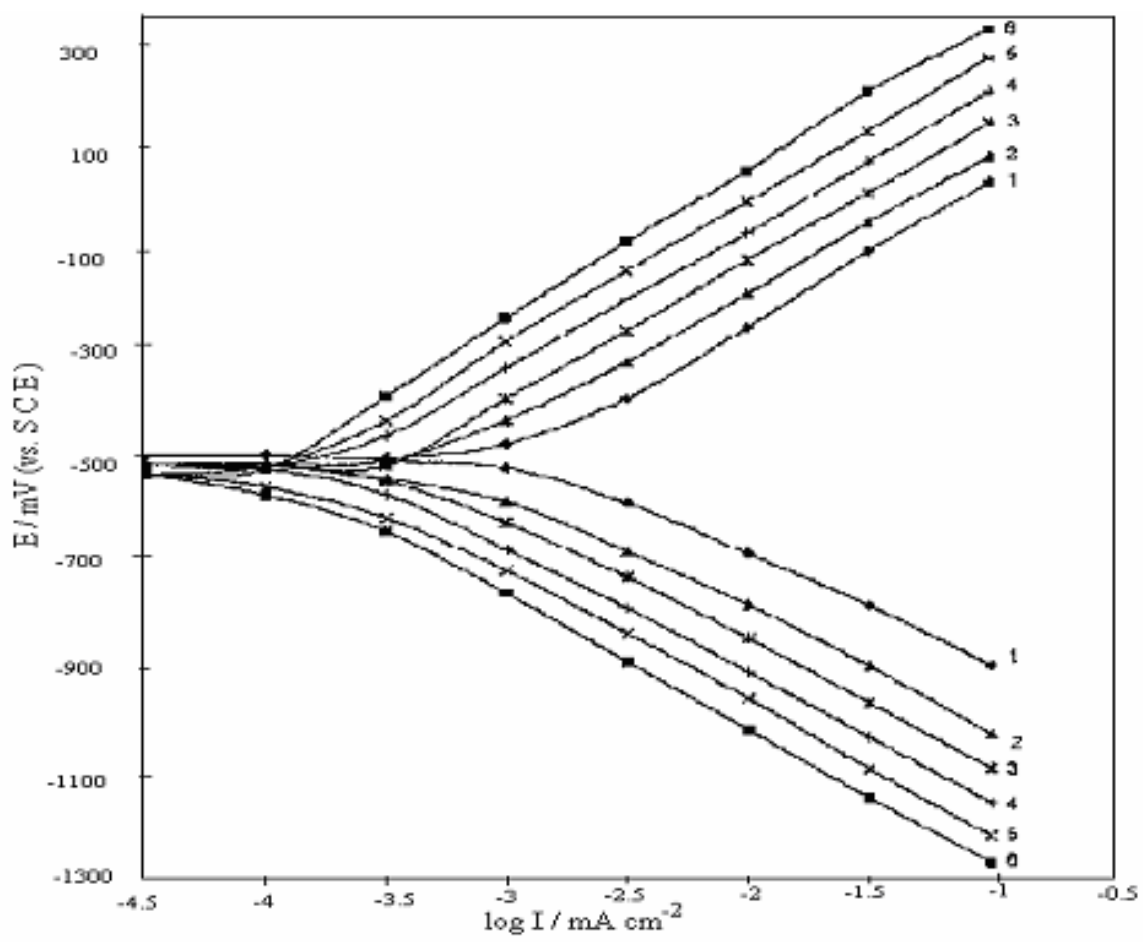

Figure 3. Anodic and cathodic Tafel polarization of C-steel in $1 \mathrm{M} \mathrm{H}_{2} \mathrm{SO}_{4}$ devoid of and containing different concentration of inhibitor: 1) $0 \mathrm{ppm}, 2) 250 \mathrm{ppm}, 3) 500 \mathrm{ppm}$, 4) $750 \mathrm{ppm}$, 5) $1000 \mathrm{ppm}, 6) 1500 \mathrm{ppm}$.

The protection efficiency $(\mathrm{P} \%)$ obtained from polarization measurements was calculated using the following equation:

$$
\mathrm{P} \%=100\left[1-\frac{\mathrm{i}_{\text {corr (add) }}}{\mathrm{i}_{\text {corr (free) }}}\right]
$$

where $i_{\text {corr(add) }}$ and $i_{\text {corr(free) }}$ are the corrosion current densities recorded in the presence and in absence of the inhibitor, respectively. 
The values of polarization resistance $\left(R_{p}\right)$ are inversely related to $i_{\text {corr }}$ through Stern-Geary equation [13].

$$
\mathrm{R}_{\mathrm{p}}=\frac{\beta_{\mathrm{c}} \beta_{\mathrm{a}}}{2.3 \mathrm{i}_{\text {corr }}\left(\beta_{\mathrm{c}}+\beta_{\mathrm{a}}\right)}
$$

and hence the lowest $\mathrm{R}_{\mathrm{p}}$ means the highest corrosion rates.

Table 2 shows the electrochemical parameters calculated from the polarization curves that allow to get the following conclusions: the Tafel constants $\left(\beta_{\mathrm{a}} \& \beta_{\mathrm{c}}\right)$ and the corrosion potential $\left(\mathrm{E}_{\text {corr. }}\right)$ are practically independent of the inhibitor concentration, which suggests that the guar gum acts as a mixed inhibitor; the corrosion current density $\left(i_{\text {corr. }}\right.$ ) decreases with the guar gum concentration which indicates its inhibiting effect; the protection efficiencies evaluated from the $i_{\text {corr }}$ or $\mathrm{R}_{\mathrm{p}}$ parameters agree well with the obtained from the experimental weight loss values. Considering the definition of the protection efficiency similar parameters, $\mathrm{P}_{\mathrm{i}}$, based in the exchange current density of the h.e.r. can be defined by the following equation:

$$
\mathrm{Pi}_{\mathrm{o}}=100\left[1-\frac{\mathrm{i}_{\mathrm{o}_{\text {(add })}}}{\mathrm{i}_{\mathrm{o}_{\text {(free })}}}\right]
$$

where $i_{o(\text { add })}$ and $i_{\text {o(free) }}$ are the exchange current densities with and without inhibitor. The ratio $\mathrm{r}=\mathrm{Pi}_{\mathrm{o}} / \mathrm{Pi}_{\text {(corr) }}$ [14] can now be used as a criterion for differentiating between cathodic rate control $(\mathrm{r}>1)$, anodic rate control $(\mathrm{r}<1)$ or mixed control $(\mathrm{r} \cong 1)$. From the values obtained in Table 2, it is clear that the values are of $r \cong 1$, which proves that the guar gum acts as mixed inhibitor.

\section{Susceptibility of C-steel to pitting corrosion by chloride ions}

The effect of the $\mathrm{NaCl}$ concentration in the pitting corrosion of the carbon steel in $1 \mathrm{M} \mathrm{H}_{2} \mathrm{SO}_{4}$ solution was examined by potentiodynamic anodic polarization technique. 
Table 2. Electrochemical parameters of C-steel corrosion in $1 \mathrm{M} \mathrm{H}_{2} \mathrm{SO}_{4}$ in the absence and presence of various concentrations of inhibitor as calculated from polarization measurements.

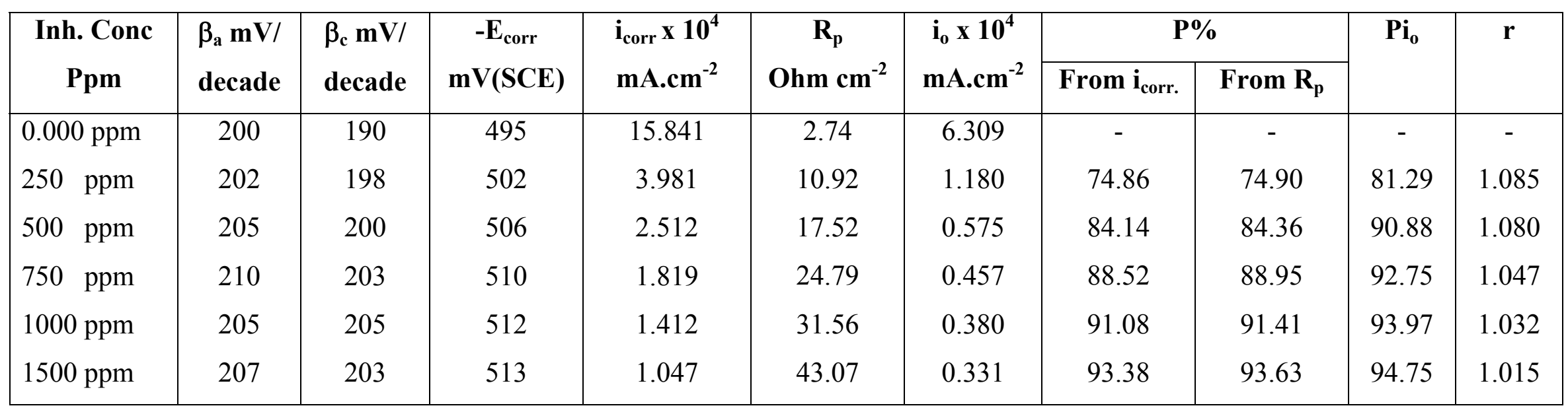




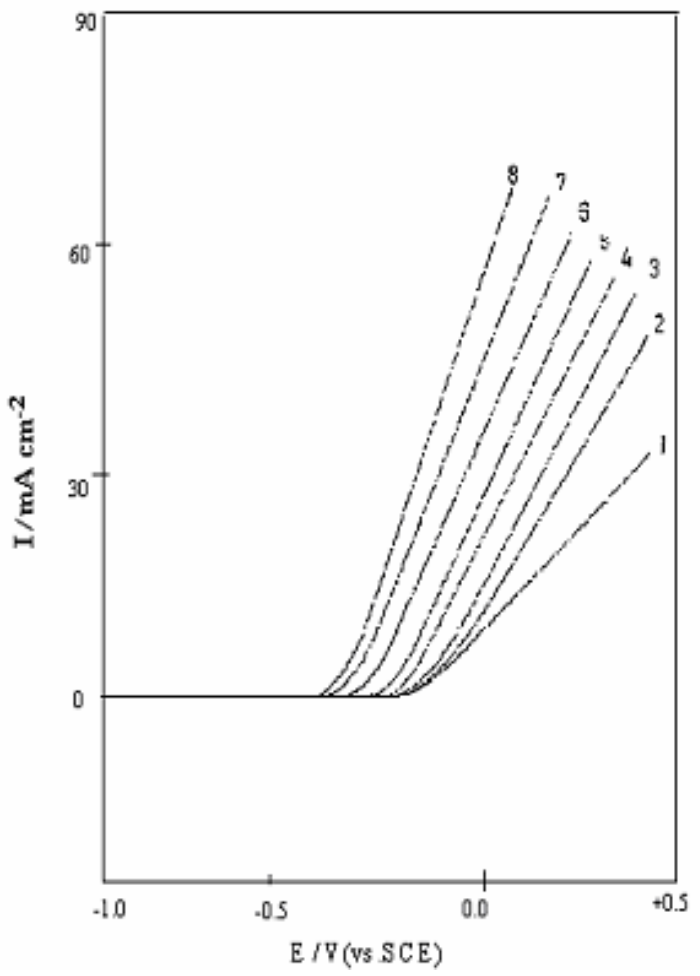

Figure 4. Potentiodynamic anodic polarization curves of $\mathrm{C}$-steel electrode in $1 \mathrm{M}$ $\mathrm{H}_{2} \mathrm{SO}_{4}$ using different concentrations of $\mathrm{NaCl}$, at a scan rate $1 \mathrm{mV} \mathrm{sec}^{-1}$.

Fig. 4 shows the potentiodynamic anodic polarization curves of $\mathrm{C}$-steel electrode in $1 \mathrm{M} \mathrm{H}_{2} \mathrm{SO}_{4}$ using different concentrations of $\mathrm{NaCl}$ at scan rate $1 \mathrm{mVs}^{-1}$. The slow scan rate permits that the pitting initiation occurs at less positive potential [15]. It is clear from the results that in the concentration range of $\mathrm{NaCl}$ studied the metal does not exhibit an active-passive transition. However, on increasing the concentration of $\mathrm{Cl}^{-}$ion, there is a sudden and marked increase of current density at a definite potential indicating the passivity breakdown and initiation of pitting corrosion [16]. The potential at which the sudden rise takes place is defined as the pitting potential $\left(\mathrm{E}_{\text {pitt. }}\right)$. The higher concentration of $\mathrm{Cl}^{-}$ion, the higher is the shift of pitting potential towards the active direction. The breakdown of passivity could be attributed to the adsorption of chloride ions on the passive film formed on the steel surface, which create an electrostatic field across film / solution interface $[17,18]$. Thus, when the electrostatic field reaches a certain value, the adsorbed anions begin to penetrate into the passive film and the pitting corrosion is initiated. 


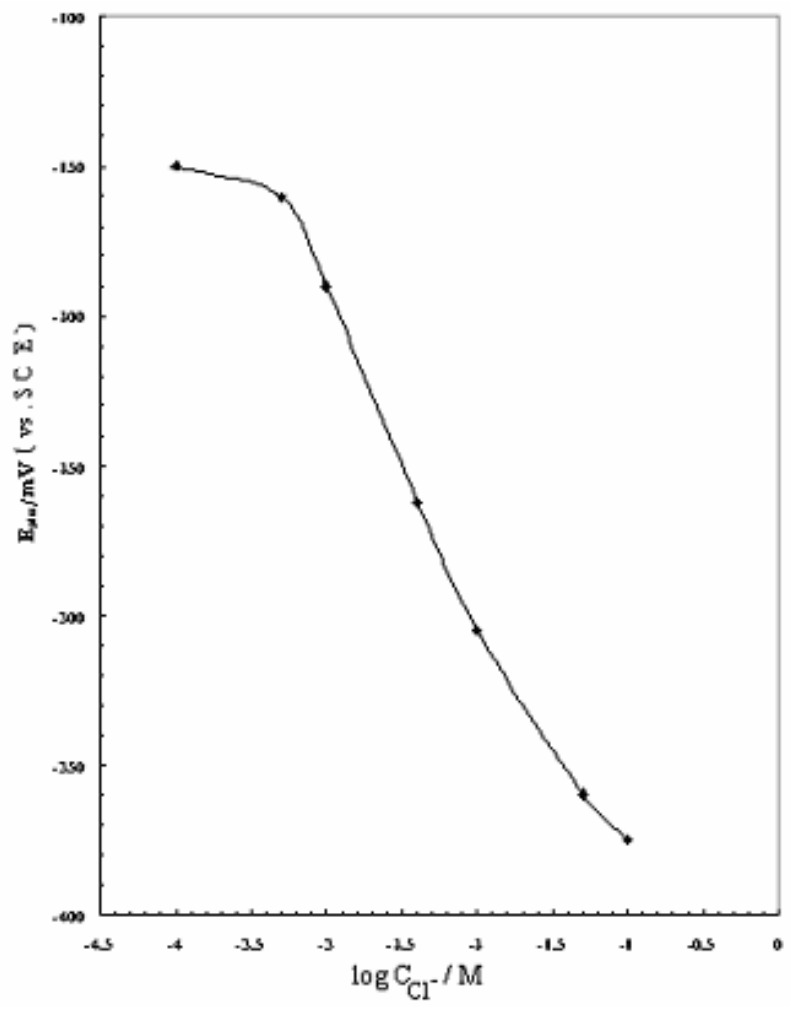

Figure 5. Variation of pitting corrosion potential $\left(\mathrm{E}_{\mathrm{pitt}}\right)$ versus $\log \mathrm{C}_{\mathrm{Cl}^{-}}$.

The dependence of $\mathrm{E}_{\text {pitt }}$ with the concentration of $\mathrm{Cl}^{-}$ion is shown in Fig. 5. The relation presents sigmoid $\mathrm{S}$-shaped curve that indicates a higher $\mathrm{E}_{\text {pitt }}$ value at the lower chloride ion concentrations. In this case, the rate of passive film formation prevails over that of film breakdown, which is clear from the small change of $E_{\text {pitt }}$ into negative direction of potential. Thus, the metal surface may undergo a repassivation $[19,20]$. However, at relatively higher $\mathrm{Cl}^{-}$ion concentrations, $\mathrm{E}_{\mathrm{pitt}}$ varies with $\mathrm{Cl}^{-}$ion concentrations according to a straight line relationship in the following forms [21]:

$$
\mathrm{E}_{\mathrm{pitt}}=\mathrm{a}_{1}-\mathrm{b}_{1} \log \mathrm{C}_{\mathrm{Cl}}
$$

where $a_{1}$ and $b_{1}$ are constant depending on both the nature and type of the aggressive anion and of the electrode. This is due to the destruction of the passive film formed on the steel surface and the pits propagate without to allow undergo the repassivation. At higher $\mathrm{Cl}^{-}$ion concentration, the film breakdown showed far 
exceeds film formation. This discussion is better explained from the (i-time) curves of Fig. 6 obtained for different concentrations of $\mathrm{Cl}^{-}$ion at the corresponding pitting potentials. Indeed at lower $\mathrm{Cl}^{-}$ion concentration, ex. $1 \times 10^{-4}$ $\mathrm{M} \mathrm{NaCl}$, the current density increases initially and then tends to a plateau indicating the repassivation of the formed pits. Meanwhile, at higher concentration of $\mathrm{Cl}^{-}$ion, ex. $1 \times 10^{-1} \mathrm{M} \mathrm{NaCl}$, the current density increases rapidly and does not reach a limiting value, which conforms with the continuous propagation of the pits already formed.

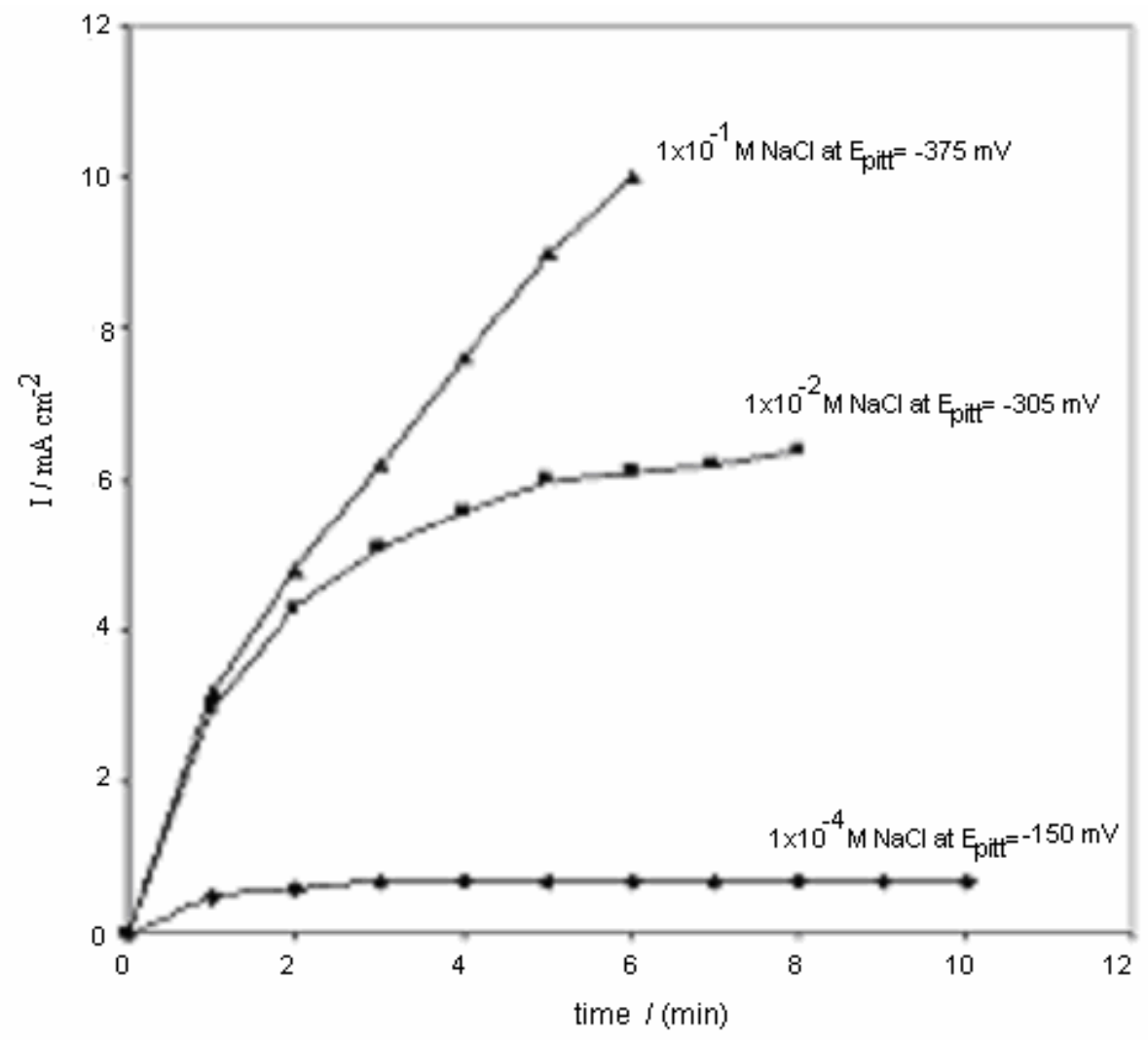

Figure 6. Current time curves of C-steel electrode in $1 \mathrm{M} \mathrm{H}_{2} \mathrm{SO}_{4}$ with different concentration of $\mathrm{NaCl}$ at the corresponding potential.

The effect of the concentration of guar gum on the potentiodynamic anodic polarization of $\mathrm{C}$-steel electrode in $\left[1 \mathrm{M} \mathrm{H}_{2} \mathrm{SO}_{4}+0.1 \mathrm{M} \mathrm{NaCl}\right]$ at a scan rate of $1 \mathrm{mVs}^{-1}$ is illustrated in Fig. 7. It was found that increasing the concentration of guar gum causes a shift of the pitting potential into noble direction indicating an increased resistance to pitting attack. 


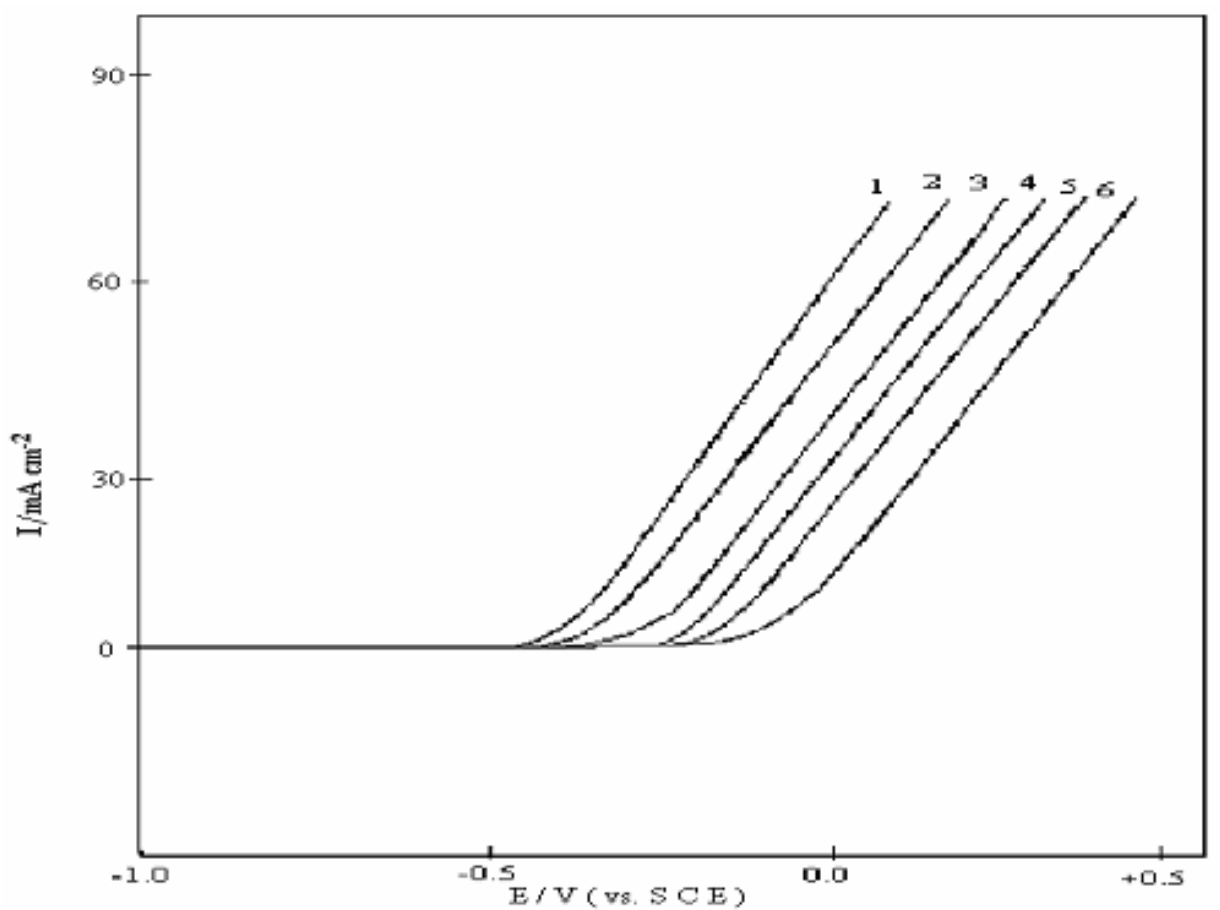

Figure 7. Potenciodynamic anodic polarization curves of C-steel in $\left(1 \mathrm{M} \mathrm{H}_{2} \mathrm{SO}_{4}+0.1\right.$ $\mathrm{M} \mathrm{NaCl}$ ) using different concentrations of inhibitor, at a scan rate $\left.1 \mathrm{mV} \mathrm{sec}^{-1} .1\right) 0 \mathrm{ppm}$, 2) $250 \mathrm{ppm}$, 3) $500 \mathrm{ppm}, 4) 750 \mathrm{ppm}$, 5) $1000 \mathrm{ppm}, 6) 1500 \mathrm{ppm}$.

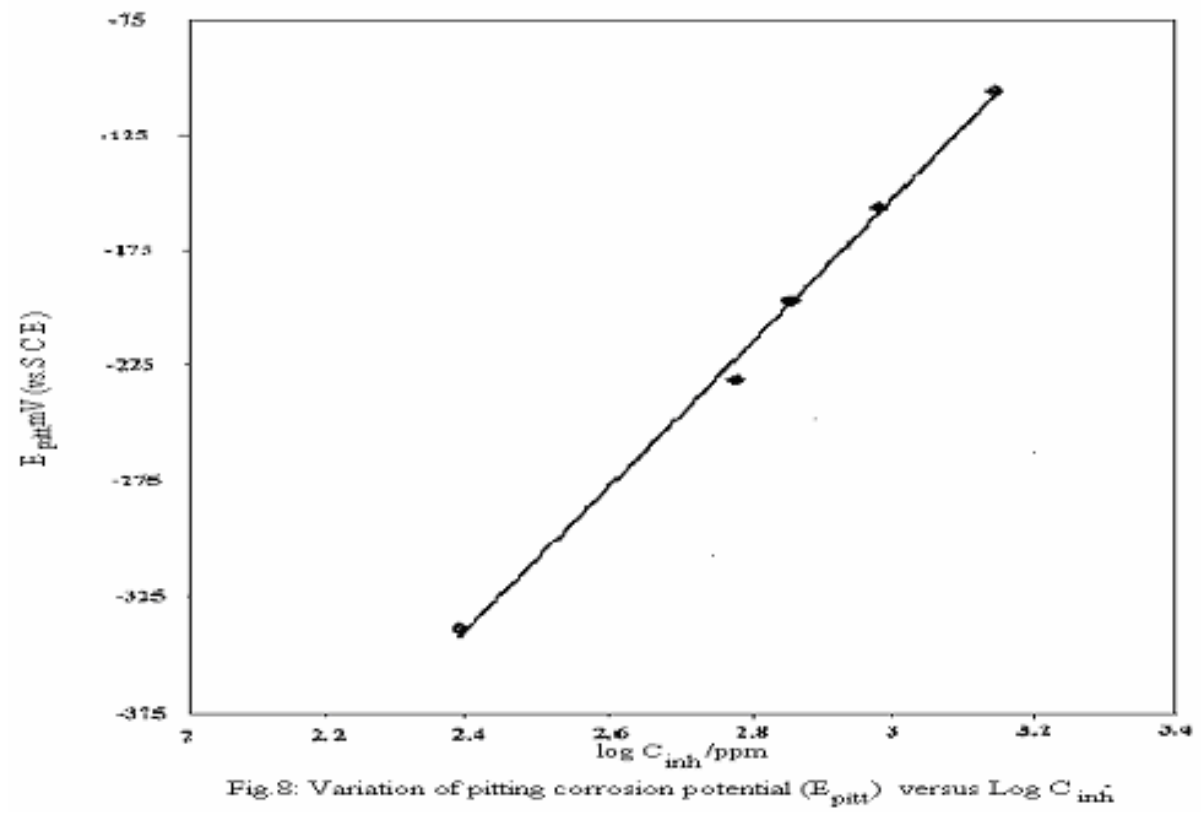

Figure 8. Variation of pitting corrosion potential ( $\left.E_{\text {pitt }}\right)$ versus $\log C_{\text {inh. }}$. 
A straight line relationship between $E_{\text {pitt }}$ and $\log C_{\text {inh. }}$ (Fig. 8) is obtained according to the equation:

$$
\mathrm{E}_{\text {pitt }}=\mathrm{a}_{2}+\mathrm{b}_{2} \log \mathrm{C}_{\mathrm{inh}}
$$

where $a_{2}$ and $b_{2}$ are constants which depend on both the type of additive and the nature of the electrode.

\section{Mechanism of inhibition}

The corrosion inhibition of C-steel by guar gum is due to the adsorption at the electrode/solution interface. Guar gum is a polysaccharide compound containing repeated heterocyclic pyrane moiety as shown in Fig. 1. The presence of hetero oxygen atom in the structure makes possible its adsorption by co-ordinate type linkage through the transfer of lone pairs of electron of oxygen atoms to the steel surface, giving a stable chelate five membered ring with ferrous ions. The chelation between $\mathrm{O}^{1}$ and $\mathrm{O}^{2}$ with $\mathrm{Fe}^{++}$seems to be impossible due to proximity factor presented as follows:

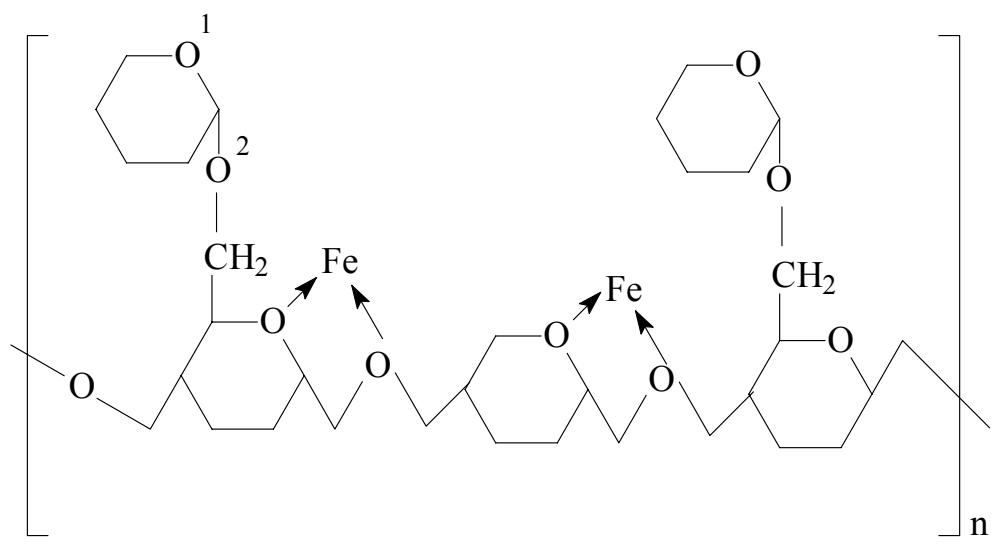

The simultaneous adsorption of oxygen atoms forces the guar gum molecule to be horizontally oriented at the metal surface, which led to increase the surface coverage and consequently protection efficiency even in the case of low inhibitor concentrations.

\section{Conclusions}


1. Guar gum acts as an inhibitor for the corrosion of C-steel in $\mathrm{H}_{2} \mathrm{SO}_{4}$ solution.

2. The inhibition action of guar gum is attributed to its horizontal adsorption on steel surface.

3. The adsorption of guar gum on steel surface in $\mathrm{H}_{2} \mathrm{SO}_{4}$ solution follows Langmuir adsorption isotherm.

4. The addition of guar gum shifts the pitting potential of C-steel electrode to more positive values indicating an increased resistance to pitting attack.

\section{References}

1. Trabanelli, Corrosion 47 (1991) 410.

2. B.A. Abd El-Nabey, E. Khamis, M.Sh. Ramadan, A. El-Gindy, Corrosion $52-9$ (1996) 671.

3. S.S. Abd El-Rehim, S.A.M. Refay, F. Taha, M.B. Saleh, R.A. Ahmed, J. Appl. Electrochem. 31 (2001) 429.

4. J.M. Bastidas, J.L. Polo, E. Cano, C.L. Torres, J. Material Sci. 35 (2000) 2637.

5. S.S. Abd El-Rehim, M.A.M. Ibrahim, K.F. Khaled, J. Appl. Electrochem. 29 (1999) 593.

6. F. Bentiss, M. Lagrenée, M. Traisnel, Corrosion 56-7 (2000) 733.

7. J. de Damborenea, J.M. Bastidas, A.J. Vazquez, Electrochimica Acta 42-3 (1997) 455.

8. J.G.N. Thomos, Proceedings of the $5^{\text {th }}$ European Symposium on Corrosion Inhibitors, Ann Univ. Ferrara, Italy, N.S. Sez V, suppl. N.8 (1980) 453.

9. P.B. Mathur, T.Vasudevam, Corrosion 38 (1982) 17.

10. B.G. Ateya, B.E. Anadouli, F.M. El-Nizamy, Bull. Chem. Soc. Japan 54 (1981) 3157.

11. S.M. Abd El- Haleem, A.A. Abd El-Fattah, W. Tayor, Res. Mechanica 30-3 (1983) 353 .

12. M.S. Morad, J. Appl. Electrochem. 29 (1999) 619.

13. M.Stren, Al-Geary, J. Electrochem Soc. 104 (1975) 56. 
14. B.G. Ateya, B.E. El-Anadouli, F.M. El-Nizamy, Corros. Sci. 24-6 (1984) 497.

15. N.G. Thompson, B.C. Syretti, Corrosion 48 (1992) 649.

16. Ja. M. Kolotyrkin, Corrosion 19 (1963) $261 \mathrm{t}$.

17. T.P. Hoar, D. Mears, G. Rothwell, Corros. Sci. 5 (1965) 279.

18. S.S. Abd El-Rehim, S.M. Abd El-Wahab, E.E. Fouad, Hamdy H. Hassan, Mater. Corros. 46 (1995) 633.

19. S.M. Abd El-Haleem, Br. Corros. J. 14 (1979) 171.

20. M.Abdallah, S.M. Abd El-Haleem, Bull. Electrochem. 12 (7-8) (1996) 449.

21. S.M. Abd El-Haleem, S.S. Abd El-Rehim, A.M. Azzam, Werkstoffe U. Korros. 27 (1976) 630. 